\title{
Mental stress and exercise training response: stress-sleep connection may be involved
}

\author{
Marcelo Marcos Piva Demarzo ${ }^{*}$ and Phyllis K. Stein ${ }^{2}$ \\ Department of Preventive Medicine, Center for Mindfulness and Health Promotion, Universidade Federal de São Paulo, São Paulo, São Paulo, Brazil \\ Division of Cardiology, Heart Rate Variability Laboratory, Washington University School of Medicine, Saint Louis, MO, USA \\ *Correspondence: marcelokele@yahoo.com.br
}

\section{A commentary on}

Self rated mental stress and exercise training response in healthy subjects by Ruuska, P. S., Hautala, A. J., Kiviniemi, A. M., Mäkikallio, T. H., and Tulppo, M. P. (2012). Front. Physio. 3:51. doi: 10.3389/ fphys.2012.00051

Ruuska et al. (2012) showed that individual responses to exercise training may vary as a function of the baseline self-rated mental stress among healthy volunteers after a highly controlled aerobic training intervention. The changes in fitness were poor or absent in the subjects who reported their psychological resources as low and reported having a lot of stressors in their lives prior to the intervention. The authors presented some potential mechanisms that could explain their findings, highlighting the role of stress-related hormonal changes in the training response. Our brief comment aims to contribute to the discussion by adding a complementary explanation that could help to clarify these interesting findings. Our hypothesis is that the connection between sleep disturbance and mental stress could also be involved in the results from Ruuska et al. (2012).

It is well known that sleep quantity and quality are associated with mental stress and vice versa (Basishvili et al., 2011; Dorrian et al., 2011; Heffner et al., 2012; Kachikis and Breitkopf, 2012; Kashani et al., 2012). Thus, it is possible that sleep deprivation lowers the psychological threshold for the perception of stress from cognitive demands (Minkel et al., 2012). Recently, Kashani et al. (2012) suggested that the stress-sleep connection may be an important mechanistic mediator of the association between stress and cardiovascular disease. In the same way, we hypothesize that stress-sleep connection may be an important mechanism in the relationship between mental stress and the exercise training response.
Sleep is widely known to be an important component of recovery from training (Leeder et al., 2012) and new data continue to elucidate the association between sleep disturbances and muscle pathophysiology. For example, Dattilo et al. (2011) hypothesized that sleep debt could, paradoxically, provoke loss of muscle mass after damage induced by exercise, hindering muscle recovery. The same research group (Dattilo et al., 2012) showed in an animal model that sleep deprivation induces a catabolic hormone profile (enhanced plasma corticosteroids and reduced serum testosterone levels) leading to muscle atrophy. Studies in athletes also have demonstrated similar results, showing that sleep deprivation is associated with reductions in: muscle glycogen and sprint performance perceptual stress (Skein et al., 2011); exercise performance by decreasing exercise minute ventilation and time to exhaustion (Azboy and Kaygisiz, 2009); anaerobic performance (Souissi et al., 2008; Taheri and Arabameri, 2012); and with enhance sports-related overtraining and acute injuries (Luke et al., 2011). Those data cannot be directly extrapolated to the general population, but is reasonable to expect that some similar processes are occurring.

Finally, the stress-sleep-training response connection has potential implication for athletic performance and should be addressed by coaches and researchers. Symptoms of chronic stress, sleep disturbances, burnout, depression, anxiety, overtraining, and addiction are prevalent among athletes (Fietze et al., 2009; Lonsdale et al., 2009; Resch, 2010). Further, athletes showed poorer markers of sleep quality than a matched nonathletic control group (Leeder et al., 2012), and disrupted sleep and disturbed dreaming are common forms of sleep deprivation in athletes the night before important competitions (Bambaeichi et al., 2005; Erlacher et al.,
2011). For this reason, as previously pointed by other investigators (Lonsdale et al., 2009; Birrer and Morgan, 2010; Kristiansen and Roberts, 2010), we also believe that psychological skills training will be progressively more relevant in future athletic training, with a special focus on balancing self-determined motivation, psychological demands, skills and techniques, social support, and a good coach-athlete relationship in order to optimally enhance performance.

\section{REFERENCES}

Azboy, O., and Kaygisiz, Z. (2009). Effects of sleep deprivation on cardiorespiratory functions of the runners and volleyball players during rest and exercise. Acta Physiol. Hung. 96, 29-36.

Bambaeichi, E., Reilly, T., Cable, N. T., and Giacomoni, M. (2005). Influence of time of day and partial sleep loss on muscle strength in eumenorrheic females. Ergonomics 48, 1499-1511.

Basishvili, T., Eliozishvili, M., Maisuradze, L., Lortkipanidze, N., Nachkebia, N., Oniani, T., Gvilia, I., and Darchia, N. (2011). Insomnia in a displaced population is related to war-associated remembered stress. Stress Health. doi: 10.1002/smi.1421. [Epub ahead of print].

Birrer, D., and Morgan, G. (2010). Psychological skills training as a way to enhance an athlete's performance in high-intensity sports. Scand. J. Med. Sci. Sports 20(Suppl. 2), 78-87.

Dattilo, M., Antunes, H. K., Medeiros, A., Mônico Neto, M., Souza, H. S., Tufik, S., and de Mello, M. T. (2011). Sleep and muscle recovery: endocrinological and molecular basis for a new and promising hypothesis. Med. Hypotheses 77, 220-222.

Dattilo, M., Antunes, H. K., Medeiros, A., Mônico-Neto, M., Souza Hde, S., Lee, K. S., Tufik, S., and de Mello, M. T. (2012). Paradoxical sleep deprivation induces muscle atrophy. Muscle Nerve 45, 431-433.

Dorrian, J., Paterson, J., Dawson, D., Pincombe, J., Grech, C., and Rogers, A. E. (2011). Sleep, stress and compensatory behaviors in Australian nurses and midwives. Rev. Saude. Publica 45, 922-930.

Erlacher, D., Ehrlenspiel, F., and Schredl, M. (2011). Frequency of nightmares and gender significantly predict distressing dreams of German athletes before competitions or games. J. Psychol. 145, 331-342.

Fietze, I., Strauch, J., Holzhausen, M., Glos, M., Theobald, C., Lehnkering, H., and Penzel, T. (2009). Sleep quality in professional ballet dancers. Chronobiol. Int. 26, 1249-1262.

Heffner, K. L., Ng, H. M., Suhr, J. A., France, C. R., Marshall, G. D., Pigeon, W. R., and Moynihan, J. A. (2012). Sleep disturbance and older adults' inflam- 
matory responses to acute stress. Am. J. Geriatr. Psychiatry. [Epub ahead of print].

Kachikis, A. B., and Breitkopf, C. R. (2012). Predictors of sleep characteristics among women in Southeast Texas. Womens Health Issues 22, e99-e109.

Kashani, M., Eliasson, A., and Vernalis, M. (2012). Perceived stress correlates with disturbed sleep: a link connecting stress and cardiovascular disease. Stress 15, 45-51.

Kristiansen, E., and Roberts, G. C. (2010). Young elite athletes and social support: coping with competitive and organizational stress in "Olympic" competition. Scand. J. Med. Sci. Sports 20, 686-695.

Leeder, J., Glaister, M., Pizzoferro, K., Dawson, J., and Pedlar, C. (2012). Sleep duration and quality in elite athletes measured using wristwatch actigraphy. $J$. Sports Sci. 30, 541-545.

Lonsdale, C., Hodge, K., and Rose, E. (2009). Athlete burnout in elite sport: a self-determination perspective. J. Sports Sci. 27, 785-795.

Luke, A., Lazaro, R. M., Bergeron, M. F., Keyser, L., Benjamin, H., Brenner, J., d'Hemecourt, P., Grady,
M., Philpott, J., and Smith, A. (2011). Sports-related injuries in youth athletes: is overscheduling a risk factor? Clin. J. Sport Med. 21, 307-314.

Minkel, J. D., Banks, S., Htaik, O., Moreta, M. C., Jones, C. W., McGlinchey, E. L., Simpson, N. S., and Dinges, D. F. (2012). Sleep deprivation and stressors: evidence for elevated negative affect in response to mild stressors when sleep deprived. Emotion. [Epub ahead of print].

Resch, M. (2010). The psychological factors affecting athletic performance. Orv. Hetil. 151, 815-821.

Ruuska, P. S., Hautala, A. J., Kiviniemi, A. M., Mäkikallio, T. H., and Tulppo, M. P. (2012). Selfrated mental stress and exercise training response in healthy subjects. Front. Physio. 3:51. doi: 10.3389/ fphys.2012.00051

Skein, M., Duffield, R., Edge, J., Short, M. J., and Mündel, T. (2011). Intermittent-sprint performance and muscle glycogen after $30 \mathrm{~h}$ of sleep deprivation. Med. Sci. Sports Exerc. 43, 1301-1311.

Souissi, N., Souissi, M., Souissi, H., Chamari, K., Tabka, Z., Dogui, M., and Davenne, D. (2008). Effect of time of day and partial sleep deprivation on short-term, high-power output. Chronobiol. Int. 25, 1062-1076.

Taheri, M., and Arabameri, E. (2012). The effect of sleep deprivation on choice reaction time and anaerobic power of college student athletes. Asian J. Sports Med. 3, 15-20.

Received: 15 May 2012; accepted: 16 May 2012; published online: 06 June 2012.

Citation: Demarzo MMP and Stein PK (2012) Mental stress and exercise training response: stress-sleep connection may be involved. Front. Physio. 3:178. doi: 10.3389/ fphys.2012.00178

This article was submitted to Frontiers in Clinical and Translational Physiology, a specialty of Frontiers in Physiology.

Copyright (c) 2012 Demarzo and Stein. This is an openaccess article distributed under the terms of the Creative Commons Attribution Non Commercial License, which permits non-commercial use, distribution, and reproduction in other forums, provided the original authors and source are credited. 